\title{
RHYNOSTELIS, GEN.N. E NOTAS SOBRE HOPLOSTELIS DOMINIQUE (HYMENOPTERA, APOIDEA, MEGACHILIDAE)
}

\author{
Jesus S. Moure ${ }^{2,3}$ \\ Danúncia Urban ${ }^{2}$
}

\begin{abstract}
RHyNostelis, gen.N. ANDTAXonomic notes on Hoplostelis DominiQue (HYMENoptera, ApoIDEA, MEgachilidaE). Rhynostelis, gen.n. is proposed as new genus for Anthidium multiplicatum Smith, 1879. It has in commom with Hoplostelis a strong basal tooth on upper border of mandibles. Main differences with Hoplostelis are: mandibular shape, configuration of mandibular teeth on apical border, a rounded tubercule on upper clypear third, mesoscutum posteriorly bigibbous, scutellum transverse-bigibbous, preepisternal carina laminate and almost complete, basal portion of propodeum without foveae and a median carina on last three terga.

KEY WORDS. Megachilidae, Rhynostelis gen.n., Hoplostelis, taxonomy
\end{abstract}

Rhynostelis, gen.n.

Espécie tipo Anthidium multiplicatum Smith, 1879.

Fêmea. Tegumento brilhante, rico em desenhos amarelos incluindo largas estrias no mesoscuto, densamente pontuado na cabeça, os pontos maiores e mais esparsos nos mesepisternos, menores e mais densos no mesoscuto, e nos tergos com pontuação mais densa e reduzida para a margem. Mandíbulas grandes, largamente dilatadas para o ápice, com forte processo dentiforme anguloso ântero-basal, metade apical inflada e a basal fortemente côncava junto ao processo dentiforme; margem apical com quatro dentes imperfeitos, o apical mais forte, o subapical em ângulo obtuso muito aberto e os dois basais mais próximos entre si; carena látero-externa curta e baixa, carena inferior externa baixa até o meio, bifurcada e fortemente aquilhada para a base; labro com tubérculo médio basal curto e transversal; clípeo achatado no disco e ápice, com um tubérculo arredondado basal mediano projetado para a frente, levemente côncavo aos lados e achatado para a sutura epistomal, bordo apical não cobrindo o labro; suturas subantenais retas e muito curtas, quase igualando o diâmetro dos alvéolos antenais; área supra-clipeal e fronte protuberantes com carena mediana baixa, sulcada nos dois terços superiores; carenas paroculares fortes; sem carena pré-ocipital; antena com escapo levemente dilatado para a base, mais curto que a distância alveolocelar lateral, pedicelo obcônico, flagelômero basal obcônico e tão longo como o

1) Contribuição número 801 do Departamento de Zoologia, Universidade Federal do Paraná.

2) Departamento de Zoologia, Universidade Federal do Paraná, Caixa Postal 19020, 81531-970 Curitiba, Paraná, Brasil.

3) Bolsista do CNPq. 
segundo, o terceiro quase tão longo como largo. Lobos pronotais com lamela curta diminuindo muito em direção ao mesoscuto; mesoscuto mais largo que longo, bigiboso no quarto posterior; escutelo transversalmente bigiboso com depressão estreita e lisa na base; axilas levemente gibosas; mesepisternos com aresta laminada pré-episternal longa, quase completa, no terço posterior elevado, em ângulo obtuso para trás caindo rapidamente em direção à cavidade coxal. Tégulas pequenas, truncadas no lado interno; asas anteriores com a veia cúbito-anal quase coincidente com a bifurcação médio-cubital, ligeiramente posterior. Canto externo das tíbias anteriores e medianas com projeção espiniforme carenada; arólios presentes. Propódeo sem fovéolas na área basal, esta separada da face vertical posterior por forte carena laminada. Tergos com depressões marginais vestigiais; carena média longitudinal vestigial do terceiro ao sexto tergo, no sexto terminando em uma profunda fóvea na frente da margem posterior levemente procurva, sem dentes laterais; primeiro tergo com grádulo fraco, não carenado; sexto esterno em baixa ogiva, sem dentes ou carena; esternos normais.

Comentário. Somente a fêmea foi examinada, contudo distingue-se dos demais Anthidiinae parasitas pelas mandíbulas largamente dilatadas para o ápice, com projeção dentiforme basal angulosa e a carena externa inferior foriemente bifurcada na metade basal; clípeo achatado no disco e ápice e com tubérculo arredondado médio basal; carena pré-episternal quase completa, laminada; mesoscuto bigiboso, como também o escutelo, este com as gibas transversas, axilas um pouco gibosas; ápice das tíbias anteriores e medianas com forte espinho carenado; base do propódeo sem fovéolas; primeiro tergo com grádulo fraco não carenado.

Este gênero tem em comum com Hoplostelis a projeção basal dentiforme angulosa das mandíbulas, porém o restante das mandíbulas é completamente diferente. Nas fềmeas de Hoplostelis as mandíbulas são alongadas com quatro dentes distintos, sendo os dois basais voltados para dentro e equidistantes ou com o terceiro separado do dente interno por amplo recorte, com carena externa inferior normal até a metade; clípeo pouco protuberante não achatado, com duas projeções espiniformes submedianas junto ao ápice, no mesmo plano do clípeo, ou com tubérculo médio-apical arredondado; fronte sem carena mediana; carena préepisternal no terço dorsal dos mesepisternos; propódeo foveolado na base, e primeiro tergo com forte carena.

\section{Rhynostelis multiplicata (Smith, 1879)}

Figs 1, 2

Smith descreveu uma fêmea como macho, coletada em São Paulo de Olivença, Amazonas, Brasil, que foi localizada por J.S. Moure na coleção do Museu Britânico, sob o número 17.a.1919. Foi examinada mais uma fêmea, esta nascida de tubo de ensaio colocado em um cupinzeiro, onde anteriormente fora vista uma Euglossini nidificando (talvez Eufriesea pulchra) em Manaus, Amazonas coletada por M.V.B. Garcia e M.L. Oliveira em 4.XI.1989.

Mensurações do exemplar de Manaus: comprimento aproximado $14 \mathrm{~mm}$; largura da cabeça 4,65 mm; do segundo segmento metasomático $5,0 \mathrm{~mm}$; compri- 
mento da asa $10 \mathrm{~mm}$; comprimento do olho $2,80 \mathrm{~mm}$; distâncias interorbitais superior e inferior $2,80 \mathrm{~mm}$ e $2,52 \mathrm{~mm}$; distâncias interocelar, ocelocular e ocelocipital: $0,56 \mathrm{~mm} ; 0,96 \mathrm{~mm} ; 1,04 \mathrm{~mm}$; diâmetro do ocelo médio $0,32 \mathrm{~mm}$; distâncias interalveolar, alveolocelar lateral e alveolorbital: $0,76 \mathrm{~mm} ; 1,40 \mathrm{~mm} ; 0,76 \mathrm{~mm}$; escapo, pedicelo e quatro flagelômeros basais: $1,32 \mathrm{~mm} ; 0,24 \mathrm{~mm} ; 0,24 \mathrm{~mm}$; $0,24 \mathrm{~mm} ; 0,32 \mathrm{~mm} ; 0,32 \mathrm{~mm}$; diâmetro do quarto flagelômero $0,36 \mathrm{~mm}$.

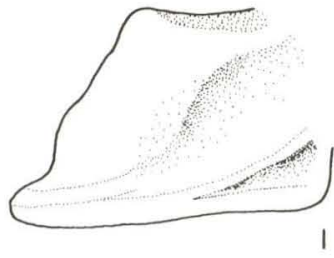

।

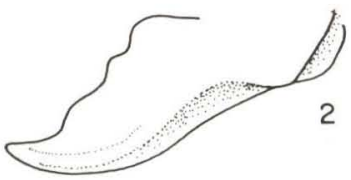

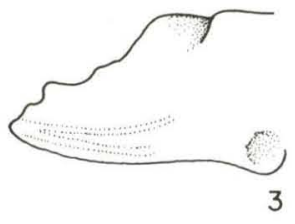
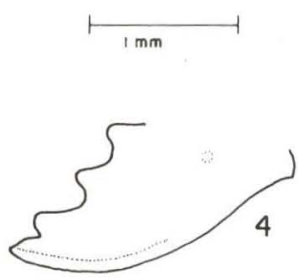

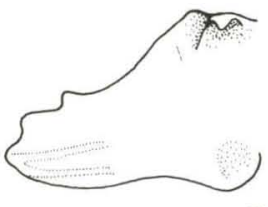

5

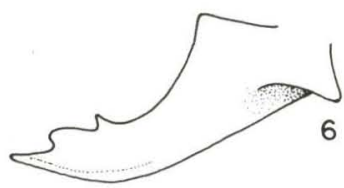

Figs 1-6. (1-2) Rhynostelis multiplicala; (3-4) Hoplostelis bivittata; (5-6) Hoplostelis comuta. Mandíbula da fềmea, respectivamente em vista lateral, com o dente basal evidente nas figuras 3 e 5 ; e em vista anterior evidenciando o bordo denteado e o dente basal, este nas figuras 2 e 6 .

\section{Hoplostelis Dominique, 1898}

Stelis (Hoplostelis) Dominique. 1898, Bull. Soc. Sci. Nat. Ouest France 8: 60.

Stelis (Odontostelis) Cockerell, 1931, Amn. Mag. Nat. Hist. 10 (8): 541-542.

Hoplostelis; Griswold \& Michener, 1988, J. Kansas Entomol. Soc. 61 (1): 36.

Dominique em 1898 deu o nome subgenérico Hoplostelis para abelhas com mandíbulas insolitamente armadas que diferiam notavelmente das outras Stelis. Este nome foi validado por Griswold e Michener em 1988, que o elevaram à categoria genérica com Stelis abnormis Friese, 1925 (= Anthidium bivittatum Cresson, 1878) como espécie tipo. O macho com o segundo esterno alongado; terceiro com franja apical de pêlos mais curtos nos lados e no meio do esterno e no restante longos e voltados para o meio, mais longos que o segundo tergo; lados do quinto esterno com lâmina arredondada sem contudo formar projeção dentiforme; lados do sexto esterno com forte dente laminado projetado para trás e $o$ bordo entre os dentes quase reto; ponta do sétimo tergo em arco rebaixado. Em Stelis aliena Cockerell, 1919 o segundo esterno do macho alongado e o terceiro com franja apical um pouco voltada para o meio porém os pêlos quase do mesmo 
comprimento, sem área distinta com pêlos mais longos; lados do quinto e sexto esternos com dente projetado para trás.

\section{Hoplostelis bilineolata (Spinola, 1841)}

Anthidium bilineolatum Spinola, 1841, Ann. Soc. Ent. France 10: 141.

Anthidium porto Friese, 1910, Deutsche ent. Ztschr.: 694

Anthidium portoi var. nigritulum Friese, 1910, Deutsche ent. Ztschr.: 694.

Stelis (Odontostelis) nectarinoda Moure, 1942. Pap. Av. 2 (21): 312.

Spinola descreveu macho e fêmea coletados em Caiena, Guiana Francesa. Ao examinar o material típico no Instituto de Zoologia da Universidade de Turin J.S. Moure verificou que o macho e a fêmea eram exemplares de gêneros diferentes, escolheu o macho como holótipo de $A$. bilineolatum por estar mais de acôrdo com a descrição de Spinola, e a fêmea identificou-a como Anthidiellum apicale (Cresson, 1878). Isto permitiu reconhecer a validade da espécie e a colocação da espécie de Friese de 1910, baseada em exemplares coletados por Ducke no Pará, em sinonímia. Quanto à variedade proposta por Friese para duas fêmeas do Espírito Santo, mais escuras, quase sem amarelo na cabeça e tórax e com larga ponta pardacenta nas asas, vale comentar a variação constatada nos espécimens examinados. O colorido das asas, mais amarelado para a base e tendendo para o enegrecido na ponta é comum às espécies conhecidas do gênero. O colorido do tegumento é bastante variável no clípeo, inteiramente amarelo em um macho coletado no Pará e preto como quase todo o restante da cabeça em um exemplar de Santa Catarina, os demais com parte do clípeo amarela e parte preta; no mesoscuto foram encontradas manchas látero-discais em forma de " $\mathrm{J}$ " invertido em machos do Peru e Mato Grosso, com as estrias discais separadas do ramo basal em um exemplar do Amapá, e duas estrias finas nos demais. Também nas fêmeas foram vistas variações nas áreas citadas acima.

O Holótipo fêmea de S. nectarinoda foi coletado em Salobra, Mato Grosso do Sul e está depositado na coleção de Entomologia Pe. Jesus Santiago Moure no Departamento de Zoologia da Universidade Federal do Paraná.

\section{Hoplostelis bivittata (Cresson, 1878)}

Figs 3, 4

Anthidium bivittatum Cresson, 1878, Tr. Amer. Ent. Soc. 7: 116.

Stelis abnormis Friese, 1925, Stett. ent.Ztg. 86: 35.

Cresson descreveu o macho de $A$. bivittatum do México, coletado por Sumichrast, cujo lectótipo, com o número 2411, foi examinado por J. S. Moure na Coleção da Academia de Ciências Naturais de Philadelphia, USA. Quanto a $S$. abnormis foi descrita de exemplares coletados em San José, Costa Rica.

Na descrição da fêmea, Friese anotou a presença de dois espinhos no clípeo, dirigidos para a frente, e de cinco dentes nas mandíbulas. Isto foi analisado por Schwarz em 1933 e pode ser observado nas figuras 3 e 4, em que o dente apical tem uma leve sinuosidade. 


\section{Hoplostelis cornuta (Bingham, 1897)}

Figs 5,6

Stelis comuta Bingham, 1897, Hym. British India 1: 497.

Descrita de Rangoon, Burma. O tipo fêmea, que está depositado na coleção do Museu Britânico com o número 17.a. 1959, foi comparado por J. S. Moure com um exemplar de Trinidad, B.W.I. o qual constatou tratar-se da mesma espécie. A dispersão se deve possivelmente ao transporte em madeira, ou conforme Griswold \& Michener, 1988, os dados sobre a localidade podem estar errados.

\section{Chave para as espécies de Hoplostelis}

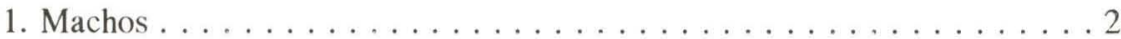

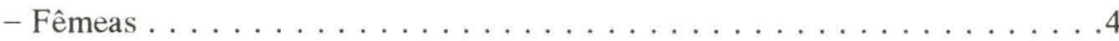

2. Labro liso, sem protuberâncias dentiformes basais. Dois tergos basais pretos, sem faixa amarela discal. México, Honduras, Costa Rica, Panamá . . . . . bivittata

- Labro com duas projeções dentiformes basais. Dois tergos basais com ou sem

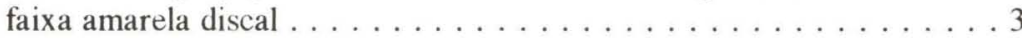

3. Mesoscuto com desenhos amarelos em faixa contínua profundamente bisinuosa ( dois "U" invertidos e unidos no ápice). Os dois tergos basais com faixa amarela discal, os demais também largamente amarelos. India, Burma (?);

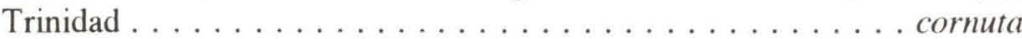

- Mesoscuto com estrias amarelas ou desenhos látero-discais em forma de J invertido. Tergo basal preto, segundo tergo preto, com nódoas laterais muito reduzidas ou formando pequenas faixas laterais amarelas. Honduras; Guiana Francesa; Guiana Inglesa; Perú; Brasil, Amapá, Amazonas, Pará, Ceará, Espírito Santo, Rio de Janeiro, São Paulo, Santa Catarina, Minas Gerais, Mato Grosso, Mato Grosso do Sul, Rondônia . . . . . . bilineolata

4. Mandíbulas largas na margem denteada, com quatro dentes equidistantes e sem largo recorte côncavo entre o terceiro e o quarto dentes; clípeo com duas projeções dentiformes apicais sub-medianas; labro com duas elevações basais fracas não formando dentes. . . . . . . . . . bivittata

- Mandibulas alongadas e estreitas para a margem apical, o dente basal afastado dos demais por longo recorte côncavo; clípeo com um tubérculo médio apical; labro com duas projeções basais dentiformes . . . . . . . . . . 5

5. Mesoscuto com desenho amarelo em forma de faixa contínua profundamente bisinuosa; todos os tergos com faixa discal amarela. . . . . . . . . cornuta

- Mesoscuto com duas estrias amarelas retas ou nódoas látero-discais em forma de $\mathrm{J}$ invertido; dois tergos basais sem faixa amarela . . . . . . . bilineolata 


\section{REFERÊNCIAS BIBLIOGRÁFICAS}

BINGHAM, C.T. 1897. The fauna of British India including Ceylon and Burma. Hymenoptera, I, Wasps and Bees. London, vol. 8, XXX+579p.

CResson, E.T. 1878. Descriptions of new North American Hymenoptera in the collection of the American Entomological Society. Trans. Amer. Ent. Soc. 7: 61-136.

Dominique, J. 1898. Coup d'oeil sur les Mellifères Sud-Américains du Muséum de Nantes. Bull. Soc. Sci. Nat. Ouest France 8: 57-65.

Friese, H. 1910. Neue Bienenarten aus Süd-Amerika. Deutsche ent. Ztschr.: 693-711.

— 1925. Neue neotropische Bienenarten, zugleich II. Nachtrag zur Bienenfauna von Costa Rica (Hym.). Stett. ent. Z. 86: 1- 41.

GRISWOLD, T.L. \& C.D. MichenER. 1988. Taxonomic observations on Anthidiini of the Western Hemisphere (Hymenoptera: Megachilidae) Journ. Kansas Ent. Soc. 61: 22-45.

Moure, J.S. 1942. Abelhas de Salobra (Hym. Apoidea). Pap. Av. II (21): 291-321.

SchwarZ, H.F. 1933. Two Stelis (Odontostelis) and a Melipona bee that have been recorded in error as Anthidiinae. Amer. Mus. Novitates 650: 1-5.

SMITH, F. 1879. Descriptions of New Species of Hymenoptera in the Collection of the British Museum. London, vol. 8, XXI+240p.

SPINOLA, M. 1841. Hymenoptères recueillis a Cayenne en 1839 par M. Leprieur. Seconde Partie: Porte-Aiguillons. Ann. Soc. Ent. Fr. 10: 85-149.

Recebido em 30.V.1994; aceito em 17.V.1994. 